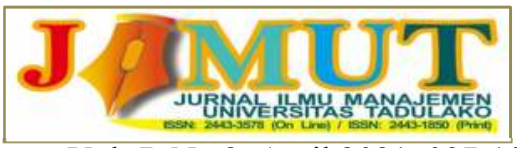

Vol. 7, No 2, April 2021, 097-106

\title{
ANALISIS BIAYA PEMELIHARAAN PERALATAN PRODUKSI PADA PABRIK TAHU SUPER AFIFAH DI KOTA PALU
}

\author{
Eka Srirahayu \\ Husein Hi Moh Saleh \\ Program Studi S1 Manajemen, Fakultas Ekonomi dan Bisnis, Universitas Tadulako \\ Email: Ayu.rahayu0797@gmail.com
}

\begin{abstract}
This Research aims to know and analyze the maintenance costs of production equipment that has been implemented by the Super Afifah Tofu factory in achieving cost efficiency. The study used qualitative methods by describing the maintenance activities undertaken by the Super Afifah Tofu Factory, as well as using quantitative methods in statistical and mathematical forms as a tool to help decide which maintenance policies will be taken in a certain period of time and measurement of efficiency using descriptive percentage. The results of this study show that, using the Preventive maintenance policy method of steam and grinding machines, resulting in the lowest preventive maintenance cost (minimum) for the vapour Keter occurring in the twelfth month of Rp. 582.213,3-, and for grinding machines the lowest preventive maintenance cost (minimum) occurred in the twelfth month of Rp. 1.492.799,9,-. Measurement of cost efficiency of repairs to steam keter amounting to Rp. 1,020,000,-with the value of efficiency is $46.12 \%$, and for the engine cost of repair of Rp. 2,550,000,-with the value of efficiency is $44.06 \%$, corresponding table efficiency that states if the calculation result below $60 \%$ is expressed very efficient.
\end{abstract}

Keywords: Maintenance, Preventative, Corrective, Cost Efficiency.

\begin{abstract}
Abstrak
Penelitian ini bertujuan untuk mengetahui dan menganalisis biaya pemeliharaan peralatan produksi yang telah diterapkan oleh Pabrik Tahu Super Afifah dalam mencapai efisiensi biaya. Penelitian ini menggunakan metode kualitatif dengan menggambarkan kegiatan pemeliharaan yang dilakukan oleh Pabrik Tahu Super Afifah, serta menggunakan metode kuantitatif dalam bentuk statistik dan matematik sebagai alat untuk membantu memutuskan kebijakan pemeliharaan yang akan diambil pada periode waktu tertentu dan pengukuran efisiensi menggunakan presentase deskriptif. Hasil penelitian ini menunjukkan bahwa, dengan menggunakan metode kebijakan pemeliharaan preventif (preventive maintenance) pada keter uap dan mesin giling, menghasilkan biaya pemeliharaan preventif yang paling rendah (minimum) untuk keter uap terjadi pada bulan ke dua belas yakni sebesar Rp. 582.213,3,- dan untuk mesin giling biaya pemeliharaan preventif yang paling rendah (minimum) terjadi pada bulan ke dua belas yakni sebesar Rp. 1.492.799,9,-. Analisis efisiensi biaya perbaikan untuk keter uap sebesar Rp. 1.020.000,- dengan nilai efisiensi adalah $46,12 \%$, dan untuk mesin giling biaya perbaikan sebesar Rp. 2.550.000,- dengan nilai efisiensi adalah 44,06\%, sesuai tabel efisiensi yang menyatakan jika hasil perhitungan dibawah $60 \%$ dinyatakan sangat efisien.
\end{abstract}

Kata Kunci : Pemeliharaan, Preventif, Korektif, Efisiensi Biaya.

\section{PENDAHULUAN}

Industri merupakan sumber yang menghasilkan serta menyediakan produk yang dibutuhkan orang banyak. Dengan demikian industri harus memperbaiki kualitas produksinya dan diikuti dengan teknologi mesin yang canggih. Untuk masuk kedalam 


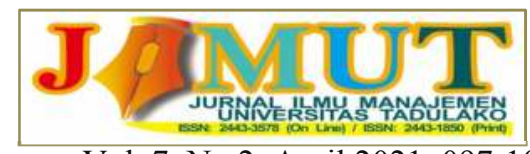

Vol. 7, No 2, April 2021, 097-106

dunia bisnis dan meningkatkan pangsa pasarnya, produk maupun jasa harus mampu menawarkan berbagai kebutuhan dan keinginan serta harapan pelanggan tersebut, perlu berbagai teknik dan suatu inovasi yang efektif dan efisien. Salah satunya ialah dengan penggunaan fasilitas dan peralatan produksi yang memiliki sistem kerja yang dirancang untuk menghasilkan kualitas yang diharapkan.

Salah satu faktor produksi yang seharusnya dimaksimalkan pemanfaatannya ialah peralatan produksi. Peralatan yang dimanfaatkan dalam aktifitas produksi harus mampu bekerja secara maksimal. Mesin dan peralatan yang berkondisi baik, sangat menunjang agar mendapatkan produk yang berkualitas. Bagi sebuah perusahaan, usaha dalam menjaga kesiapan mesin agar tetap terjaga dan tetap kontinuitas, maka dibutuhkan perawatan dan pemeliharaan terhadap mesin-mesin dan peralatan secara teratur.

Peranan proses pemeliharaan beralih sejalan dengan ketentuan pertumbuhan persaingan yang mendunia. Fungsi tersebut bukan hanya sebatas aktivitas yang mendesak guna membatasi kerusakan yang terjadi. Dengan ditetapkan struktur, infrastruktur, proses dan produksi yang benar serta konsisten, sehingga pemeliharaan bisa meminimalisir kerugian yang terjadi, operasional perusahaan dapat lebih stabil, hasil produksi bisa maksimal serta produk dengan kualitas terbaik dapat dihasilkan dengan konsisten (Mobley, 2008).

Pabrik Tahu Super Afifah merupakan salah satu industri yang berada di Sulawesi Tengah. Pabrik Tahu Super Afifah mulai berdiri pada tahun 2004 dan mulai melakukan proses produksi pada 11 Maret tahun 2004. Industri ini memproduksi bahan baku kedelai menjadi tahu. Dalam melakukan proses produksinya pabrik tahu Super Afifah memiliki 3 jenis mesin produksi, diantaranya

Tabel 1. Jenis Mesin Produksi Pabrik Tahu Super Afifah

\begin{tabular}{ccc}
\hline No & Jenis Mesin & Prosesnya \\
\hline 1 & Keter Uap & Proses merebus air sehingga menghasilkan uap \\
2 & Mesin Giling & Proses menggiling bahan baku kedelai \\
3 & Mesin Saring & Proses memisahkan ampas dan sari kedelai \\
\hline
\end{tabular}

Sumber : Pemilik Pabrik Tahu Super Afifah.

Dari ketiga jenis mesin tersebut mesin yang paling dominan atau yang paling sering mengalami kerusakan yaitu keter uap dan mesin giling. Keter uap harus selalu sesuai standar, karena keter uap merupakan salah satu mesin yang mudah meledak jika tekanan terlalu tinggi dan mesin tidak sesuai dengan standar.

\section{KAJIAN LITERATUR}

\section{Pengertian Manajemen Operasi}

Manajemen Operasi merupakan sebuah disiplin ilmu atau profesi yang mengkaji secara praktis mengenai proses perencanaan (process of plan-ning), mendesain produk (product designing), sistem produksi (production system) agar tercapai tujuan organisasi.(Prawirosentono, 2009). Menurut Handoko(2014 : 3), Manajemen Operasi ialah cara mengelola secara optimal pemanfaatan sumber daya atau dikenal dengan aspek-aspek produksi, tenaga kerja, mesin-mesin, peralatan, bahan baku dan lainnya, dalam proses mentransformasikan bahan baku menjadi berbagai produk atau jasa. Sedangkan Subagyo(2000), mendefinisikan Manajemen Operasi yaitu sebuah aktifitas 


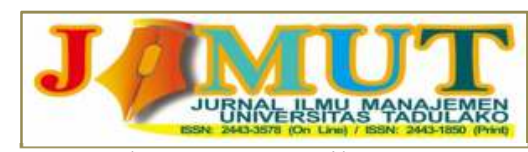

Vol. 7, No 2, April 2021, 097-106

untuk mengubah masukan (yang berupa faktor-faktor produksi/operasi) menjadi keluaran agar lebih berguna dari model aslinya.

\section{Pengertian Pemeliharaan}

Pemeliharaan merupakan suatu kegiatan untuk memelihara dan menjaga fasilitas/peralatan pabrik serta melakukan perbaikan atau penyesuaian/penggantian yang diperlukan agar terdapat suatu kondisi operasi produksi yang memadai sesuai dengan apa yang telah dirancang(Assauri, 2008). Sedangkan Reksohadiprojo(2003), mengemukakan bahwa pemeliharaan merupakan segala aktivitas yang dirancang atau dibangun sedemikian rupa sehingga sarana dan aktivitas lain dalam keadaan yang dapat menunjang tujuan organisasi. Pemeliharaan pada akhirnya meminimumkan biaya pemeliharaan jangka panjang.

\section{Jenis-jenis Pemeliharaan}

Menurut Prawirosentono(2009 : 329-330), Maintenance terbagi menjadi beberapa kriteria diantaranya sebagai berikut :

1.Pemeliharaan terencana (planned maintenance) yaitu kegiatan perawatan yang dilakukan berdasarkan perencanaan terlebih dahulu. Perencanaa pemeliharaan ini mengacu pada serangkaian proses produksi. Planned maintenance terdiri dari :

a.Pemeliharaan pencegahan (preventive maintenance) yang dilaksanakan pada periode waktu yang tetap atau dengan kriteria tertentu pada berbagai tahap proses produksi, sehingga produk yang dihasilkan sesuai dengan rencana, baik mutu, biaya, maupun ketepatan waktu. Pemeliharaan pencegahan terbagi menjadi 2, yaitu : Perawatan Berjalan (Running Maintenance), yakni kegiatan perawatan yang dilakukan pada waktu proses produksi sedang berjalan, dan Perawatan Waktu Istirahat (Shutdown Maintenance), yakni kegiatan perawatan yang dilakukan pada waktu proses produksi sedang dihentikan.

b.Pemeliharaan koreksi (corrective maintenance) merupakan perawatan yang dilakukan karena adanya hasil produk (setegah jadi maupun barang jadi) tidak sesuai dengan rencana, baik mutu, biaya, maupun ketepatan waktunya. Misalnya : terjadi kekeliruan dalam mutu/bentuk barang maka perlu diamati tahap kegiatan proses produksi yang perlu diperbaiki (koreksi).

2. Pemeliharaan Tidak Terencana (Unplanned Maintenance) adalah pemeliharaan yang dilakukan karena adanya indikasi atau petunjuk bahwa adanya tahap kegiatan proses produksi yang tiba tiba memberikan hasil yang tidak layak. Dalam hal ini perlu dilakukan kegiatan pemeliharaan atas mesin secara tidak berencana yakni pemeliharaan darurat (Emergency Maintenance), yakni kegiatan perawatan mesin yang memerlukan penanggulangan yang bersifat darurat agar tidak menimbulkan akibat yang lebih parah.

\section{METODE PENELITIAN}

Jenis penelitian ini merupakan jenis penelitian studi kasus yaitu penelitian yang dilakukan secara intensif, terinci dan mendalam terhadap objek suatu organisme, lembaga atau gejala-gejala tertentu yang diteliti. Arikunto (2002: 115). Adapun studi kasus yang dibahas pada penelitian ini yaitu mengenai kebijakan pemeliharaan peralatan produksi pada Pabrik Tahu Super Afifah. 


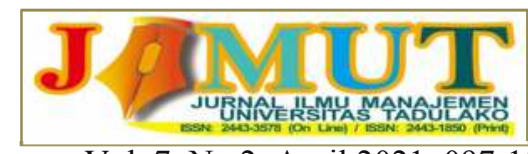

Vol. 7, No 2, April 2021, 097-106

Objek penelitian yang dimaksud dalam penelitian ini adalah Pabrik Tahu Super Afifah. Perusahaan ini beralamat di Jalan Jati No.81 Kelurahan Nunu Kecamatan Palu Barat Kota Palu. Lokasi ini dipilih dengan sengaja dengan mempertimbangkan bahwa pabrik tahu super afifah merupakan salah satu usaha yang memproduksi bahan baku kedelai menjadi tahu setiap hari, dan mesin produksi bekerja selama 9 jam per hari serta mengelolah bahan baku sebanyak 3 ton perhari.

Metode analisis yang digunakan adalah metode kuantitatif. Metode kuantitatif merupakan suatu bentuk analisis data dengan menggunakan statistik dan matematik sebagai alat untuk memperoleh sistem pemeliharaan, untuk membantu memutuskan kebijakan pemeliharaan yang akan diambil pada suatu jangka waktu tertentu. kebijakan pemeliharaan sebagai berikut :

a. Pemeliharaan terencana, Reksohadiprodjo(2003 : 427) mengemukakan Kebijakan pemeliharaan terencana didasarkan pada model probabilitas. Model ini memerlukan data biaya, pelayanan pemeliharaan pencegahan, biaya perbaikan dan probabilitas kerusakan. Probabilitas kerusakan mencerminkan bahwa kerusakan akan terjadi walaupun sudah dilakukan pemeliharaan pencegahan.

$$
B_{n=} \mathrm{N} \sum_{1}^{n} P n+\mathrm{B}(\mathrm{n}-1) P_{1}+\mathrm{B}(\mathrm{n}-2) P_{2}+\ldots . .+B_{1} \mathrm{P}(\mathrm{n}-1)
$$

Keterangan: $\quad B_{n}=$ Ekspektasi jumlah kerusakan mesin dalam $\mathrm{n}$ bulan

$\mathrm{N}=$ Jumlah mesin

$P_{n}=$ Probabilitas mesin rusak dalam periode $\mathrm{n}$

b. Pemeliharaan Perbaikan (Koreksi), Mesin pada pada Pabrik Tahu Super Afifah sangatlah sering digunakan bahka setiap hari selalu beroperasi selama 9 jam per hari, sehingga kegiatan pemeliharaannya secara berkala perlu dilakukan.

Dimana :

$$
C=\frac{(F)(R 1)}{R 0 . P}
$$

$\mathrm{C} \quad=$ Biaya perbulan pemeliharaan

$\mathrm{F} \quad=$ Banyaknya fasilitas

R1 = Biaya perbaikan

R0 = periode antar kerusakan

$\mathrm{P}=$ probabilitas rusak.

c. Indikator Atau Ukuran Efisiensi Biaya, Manajemen pemeliharaan mengutamakan pencapaian efisiensi, efisiensi adalah ukuran yang membandingkan rencana penggunaan masukan dengan realisasi penggunaannya. Pengukuran efisiensi ini digunakan untuk melihat kebijakan pemeliharaan mana yang mencapai efisiensi biaya.

$$
\text { Efisiensi }=\frac{\text { Biaya Pemeliharaan yang diperoleh }}{\text { Biaya Pemeliharaan Keseluruhan }} \times 100 \%
$$




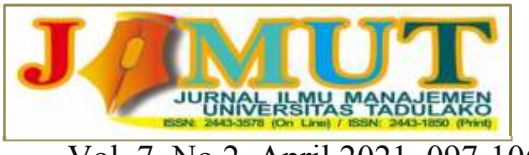

Vol. 7, No 2, April 2021, 097-106

Tabel 2. Kriteria Efisiensi

\begin{tabular}{cc}
\hline Presentase Kinerja & Kriteria \\
\hline $100 \%$ keatas & Tidak Efisien \\
$90 \%-100 \%$ & Kurang Efisien \\
$80 \%-90 \%$ & Cukup Efisien \\
$60 \%-80 \%$ & Efisien \\
Di bawah dari $60 \%$ & Sangat Efisien \\
\hline
\end{tabular}

Sumber : Mardiasmo(2004:133).

\section{HASIL DAN PEMBAHASAN}

Dari hasil pengumpulan data yang dilakukan dibulan juli 2019 peneliti dapat mengetahui bahwa pabrik tahu super afifah memiliki 3 jenis mesin produksi, namun mesin yang sering mengalami kerusakan yaitu keter uap dan mesin giling. Sistem pemeliharaan yang diterapkan di pabrik tahu super afifah ini tidak memiliki jadwal khusus dalam melakukan kegiatan pemeliharaan, sehingga dalam kegiatan proses produksi seringkali terjadi hambatan yang tidak terduga seperti pada saat proses penggilingan bahan baku mesing giling sering mengalami kerusakan akibat adanya campuran batu atau kerikil yang ikut tergiling dengan bahan baku kedelai atau tersangkut dalam batu giling dan kekurangan air pada saat penggilingan.

Selain pada proses penggilingan terkadang pada proses penguapan juga sering terjadi kendala yang menyebabkan kerusakan pada mesin keter uap seperti lepasnya baut keter yang disebabkan terlalu tingginya suhu keter. Sedangkan pada mesin saring kendala yang sering dialami yaitu tersangkutnya sarung saringan pada benda tajam saat proses penyaringan sehingga saringan robek (rusak).

Berikut disajikan data mengenai jumlah kerusakan keter uap ditahun 2018 berdasarkan probabilitas :

Tabel 3. Periode Kerusakan Keter Uap Berdasarkan Probabilitas

\begin{tabular}{ccccc}
\hline No & Periode & $\begin{array}{c}\text { Jumlah } \\
\text { Kerusakan }\end{array}$ & $\begin{array}{c}\text { Probabilitas } \\
\mathbf{( \% )}\end{array}$ & $\begin{array}{c}\text { Probabilitas (\%) } \\
\text { Kumulatif }\end{array}$ \\
\hline 1 & Januari & 3 & 0,062 & 0,062 \\
2 & February & 3 & 0,062 & 0,124 \\
3 & Maret & 4 & 0,084 & 0,208 \\
4 & April & 4 & 0,084 & 0,292 \\
5 & Mei & 3 & 0,062 & 0,354 \\
6 & Juni & 3 & 0,062 & 0,416 \\
7 & Juli & 5 & 0,104 & 0,52 \\
8 & Agustus & 3 & 0,062 & 0,582 \\
9 & September & 5 & 0,104 & 0,686 \\
10 & Oktober & 7 & 0,146 & 0,832 \\
11 & November & 4 & 0,084 & 0,916 \\
12 & Desember & 4 & 0,084 & 1 \\
\hline \multicolumn{2}{c}{ Jumlah } & 48 & 1 & \\
\hline
\end{tabular}

Sumber: Data Setelah Diolah

Adapun data mengenai jumlah kerusakan mesin giling ditahun 2018 berdasarkan probabilitas dapat dilihat pada Tabel 4 di bawah ini: 


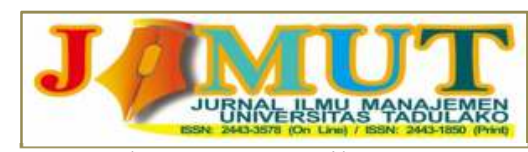

Vol. 7, No 2, April 2021, 097-106

Tabel 4. Periode Kerusakan Mesin Giling Berdasarkan Probabilitas

\begin{tabular}{ccccc}
\hline No & Periode & $\begin{array}{c}\text { Jumlah } \\
\text { Kerusakan }\end{array}$ & Probabilitas (\%) & $\begin{array}{c}\text { Probabilitas } \\
\text { (\%) } \text { Kumulatif }\end{array}$ \\
\hline 1 & Januari & 5 & 0,104 & 0,104 \\
2 & February & 2 & 0,042 & 0,146 \\
3 & Maret & 3 & 0,062 & 0,208 \\
4 & April & 4 & 0,084 & 0,292 \\
5 & Mei & 6 & 0,125 & 0,417 \\
6 & Juni & 2 & 0,042 & 0,459 \\
7 & Juli & 4 & 0,084 & 0,543 \\
8 & Agustus & 3 & 0,062 & 0,605 \\
9 & September & 5 & 0,104 & 0,709 \\
10 & Oktober & 7 & 0,145 & 0,854 \\
11 & November & 4 & 0,084 & 0,938 \\
12 & Desember & 3 & 0,062 & 1 \\
\hline \multicolumn{7}{c}{ Jumlah } & 48 & 1 & \\
\hline
\end{tabular}

Sumber : Data Setelah Diolah

Perhitungan mengenai keseluruhan ekspektasi kerusakan mesin tiap $n$ bulan, rata-rata kerusakan perbulan, biaya perbaikan kerusakan mesin perbulan, biaya pemeliharaan terencana (preventif) perbulan, dan total biaya pemeliharaan perbulan untuk keter uap dapat dilihat pada Tabel 5 di bawah ini :

Tabel 5. Perhitungan Biaya Pemeliharaan Preventif Untuk Dua Belas Bulan Pemeliharaan Yang Berbeda Pada Keter Uap

\begin{tabular}{|c|c|c|c|c|c|}
\hline $\begin{array}{c}\text { (a) } \\
\text { Pemeliharaa } \\
\text { n preventif } \\
\text { tiap n bulan }\end{array}$ & $\begin{array}{c}\text { Jumlah } \\
\text { kerusakan } \\
\text { yang } \\
\text { diperkirakan } \\
\text { dalam n bulan }\end{array}$ & $\begin{array}{c}\text { Jumlah rata } \\
\text { kerusakan } \\
\text { perbulan }\end{array}$ & $\begin{array}{c}\text { (d) } \\
\text { Ekspektasi } \\
\text { biaya } \\
\text { kerusakan } \\
\text { yang } \\
\text { diperkiraka } \\
\text { n perbulan }\end{array}$ & $\begin{array}{c}\text { (e) } \\
\text { Biaya } \\
\text { pemeliharaan } \\
\text { preventif yang } \\
\text { diperkirakan } \\
\text { perbulan }\end{array}$ & $\begin{array}{c}\text { (f) } \\
\text { Biaya sub } \\
\text { kebijaksanaa } \\
\text { n } \\
\text { pemeliharaan } \\
\text { bulanan total } \\
\text { yang } \\
\text { diperlukan }\end{array}$ \\
\hline & & $(\mathrm{c})=(\mathrm{b}) /(\mathrm{a})$ & $\begin{array}{c}(\mathrm{d})=(\mathrm{c}) \mathrm{x} \text { Rp. } \\
1.020 .000\end{array}$ & $\begin{array}{c}(\mathrm{e})=(1 / \mathrm{a}) \mathrm{x} \\
\mathrm{Rp} .2 .000 .000 \times 2\end{array}$ & $(\mathrm{f})=(\mathrm{d})+(\mathrm{e})$ \\
\hline 1 & 0,124 & 0,124 & 126.480 & 4.000 .000 & 4.126 .480 \\
\hline 2 & 0,256 & 0,128 & 130.560 & 2.000 .000 & 2.130 .560 \\
\hline 3 & 0,44 & 0,147 & 149.940 & $1.333 .333,3$ & $1.483 .273,3$ \\
\hline 4 & 0,633 & 0,158 & 161.160 & 1.000 .000 & 1.161 .160 \\
\hline 5 & 0,806 & 0,161 & 164.220 & 800.000 & 964.220 \\
\hline 6 & 0,986 & 0,164 & 167.280 & $666.666,7$ & $833.946,7$ \\
\hline 7 & 1,264 & 0,181 & 184.620 & $571.428,6$ & $756.048,6$ \\
\hline 8 & 1,475 & 0,184 & 187.680 & 500.000 & 687.680 \\
\hline 9 & 1,793 & 0,199 & 202.980 & $444.444,4$ & $647.424,4$ \\
\hline 10 & 2,218 & 0,222 & 226.440 & 400.000 & 626.440 \\
\hline 11 & 2,553 & 0,232 & 236.640 & $363.636,4$ & $600.276,4$ \\
\hline 12 & 2,926 & 0,244 & 248.880 & $333.333,3$ & $582.213,3$ \\
\hline
\end{tabular}

Sumber : Data Setelah Diolah 


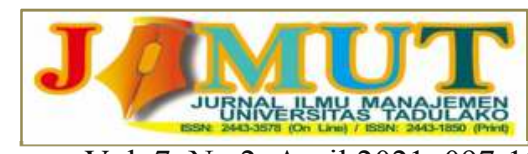

Vol. 7, No 2, April 2021, 097-106

Pada Tabel tersebut, dapat diketahui bahwa total biaya pemeliharaan yang paling rendah (minimum) untuk keter uap terjadi pada bulan ke dua belas yakni sebesar Rp. $582.213,3,-$, yang artinya untuk meminimalisir biaya pemeliharaan perusahaan seharusnya melakukan pemeliharaan pada bulan ke dua belas.

Perhitungan mengenai keseluruhan ekspektasi kerusakan mesin tiap $\mathrm{n}$ bulan, rata-rata kerusakan perbulan, biaya perbaikan kerusakan mesin perbulan, biaya pemeliharaan terencana (preventif) perbulan, dan total biaya pemeliharaan perbulan untuk mesin giling dapat dilihat pada Tabel 6 di bawah ini :

Tabel 6. Perhitungan Biaya Pemeliharaan Preventif Untuk Dua Belas Bulan Pemeliharaan Yang Berbeda Pada Mesin Giling

\begin{tabular}{|c|c|c|c|c|c|}
\hline $\begin{array}{c}\text { (a) } \\
\text { Pemeliharaa } \\
\text { n preventif } \\
\text { tiap n bulan }\end{array}$ & $\begin{array}{c}\text { (b) } \\
\text { Jumlah } \\
\text { kerusakan } \\
\text { yang } \\
\text { diperkirakan } \\
\text { dalam n } \\
\text { bulan }\end{array}$ & $\begin{array}{c}\text { (c) } \\
\text { Jumlah rata } \\
\text { kerusakan } \\
\text { perbulan }\end{array}$ & $\begin{array}{c}\text { (d) } \\
\text { Ekspektasi } \\
\text { biaya } \\
\text { kerusakan } \\
\text { yang } \\
\text { diperkirakan } \\
\text { perbulan }\end{array}$ & $\begin{array}{c}\text { (e) } \\
\text { Biaya } \\
\text { pemeliharaan } \\
\text { preventif yang } \\
\text { diperkirakan } \\
\text { perbulan }\end{array}$ & $\begin{array}{c}\text { (f) } \\
\text { Biaya sub } \\
\text { kebijaksan } \\
\text { aan } \\
\text { pemelihara } \\
\text { an bulanan } \\
\text { total yang } \\
\text { diperlukan }\end{array}$ \\
\hline & & $(\mathrm{c})=(\mathrm{b}) /(\mathrm{a})$ & $\begin{array}{c}\text { (d)=(c)x Rp. } \\
2.550 .000\end{array}$ & $\begin{array}{c}(\mathrm{e})=(1 / \mathrm{a}) \mathrm{x} \\
\mathrm{Rp} .5 .040 .000 \times 2\end{array}$ & (f)=(d)+(e) \\
\hline 1 & 0,208 & 0,208 & 530.400 & 10.080 .000 & 10.610 .400 \\
\hline 2 & 0,314 & 0,157 & 400.350 & 5.040 .000 & 5.440 .350 \\
\hline 3 & 0,458 & 0,153 & 390.150 & $3.359 .999,9$ & $3.750 .149,9$ \\
\hline 4 & 0,658 & 0,164 & 418.200 & 2.520 .000 & 2.938 .200 \\
\hline 5 & 0,957 & 0,191 & 487.050 & 2.016 .000 & 2.503 .050 \\
\hline 6 & 1,041 & 0,173 & 441.150 & 1.680 .000 & 2.121 .150 \\
\hline 7 & 1,361 & 0,194 & 494.700 & 1.440 .000 & 1.934 .700 \\
\hline 8 & 1,597 & 0,199 & 507.450 & 1.260 .000 & 1.767 .450 \\
\hline 9 & 1,926 & 0,214 & 545.700 & $1.119 .999,9$ & $1.665 .699,9$ \\
\hline 10 & 2,326 & 0,233 & 594.150 & 1.008 .000 & 1.602 .150 \\
\hline 11 & 2,728 & 0,248 & 632.400 & $916.363,6$ & $1.548 .763,6$ \\
\hline 12 & 3,073 & 0,256 & 652.800 & $839.999,9$ & $1.492 .799,9$ \\
\hline
\end{tabular}

Sumber : Data Setelah Diolah

Pada Tabel tersebut, dapat diketahui bahwa total biaya pemeliharaan yang paling rendah (minimum) untuk mesin giling terjadi pada bulan ke dua belas yakni sebesar Rp. 1.492.799,9,-, yang artinya untuk meminimalisir biaya pemeliharaan perusahaan seharusnya melakukan pemeliharaan pada bulan ke dua belas.

Adapun untuk menghitung biaya yang dikeluarkan jika melaksanakan kebijakan pemeliharaan secara korektif dan untuk mengetahui jumlah bulan yang diperkirakan antar kerusakan dari kedua mesin tersebut, dapat disajikan pada Tabel 7 berikut ini: 


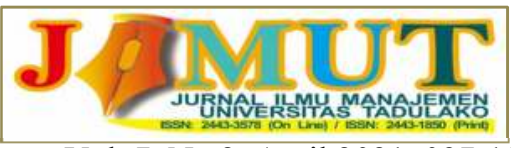

Vol. 7, No 2, April 2021, 097-106

Tabel 7 Perhitungan Untuk Mencari Jumlah Bulan yang Diperkirakan Antar Kerusakan

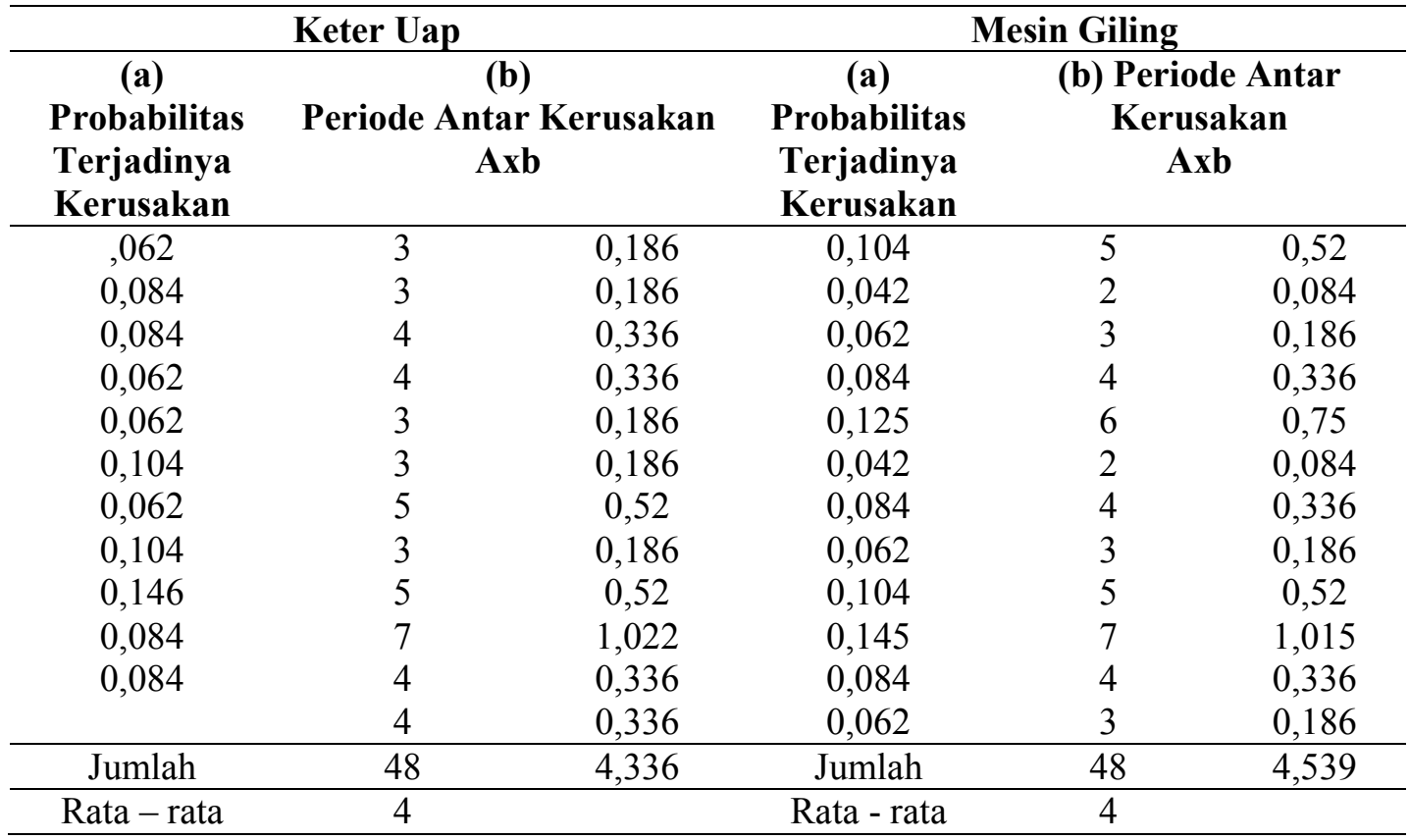

Sumber : Data Setelah Diolah

Biaya total pemeliharaan korektif pertahun untuk keter uap adalah:

$$
T C=\frac{2 \times \text { Rp. } 1.020 \cdot 000,-}{4,336}=\text { Rp. 470.480,- }
$$

Biaya total pemeliharaan korektif pertahun untuk mesin giling adalah:

$$
T C=\frac{2 \times \text { Rp. } 2 \cdot 550 \cdot 000,-}{4,539}=\text { Rp. 1.123.596, }-
$$

Dari perhitungan tersebut, dapat diketahui bahwa untuk total biaya pemeliharaan korektif pada keter uap sebesar Rp.470.480,- dan total biaya pemeliharaan korektif mesin giling sebesar Rp.1.123.596,-.

Dari hasil perhitungan total biaya pemeliharaan preventif dan total biaya kerusakan (korektif) pada keter uap dan mesing giling berikut disajiakan pada Tabel 8 berikut ini:

Tabel 8 Perbandingan Total Biaya Pemeliharaan Preventif dengan Total Biaya Korektif

\begin{tabular}{lll}
\hline \multicolumn{1}{c}{ Jenis Mesin } & \multicolumn{1}{c}{$\begin{array}{c}\text { Total Biaya Pemeliharaan } \\
\text { Preventif }\end{array}$} & \multicolumn{1}{c}{ Total Biaya Korektif } \\
\hline Keter Uap & Rp. $582.213,3,-$ & Rp. $470.480,-$ \\
Mesin Giling & Rp. 1.492.799,9,- & Rp. 1.123.596,- \\
\hline Sumber: Data setelah diolah &
\end{tabular}




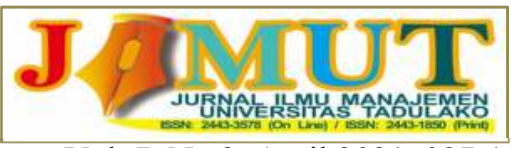

Vol. 7, No 2, April 2021, 097-106

\section{Analisis Efisiensi Biaya \\ Biaya Pemeliharaan Preventive}

\section{Keter Uap}

Efisiensi $\frac{\text { Rp.582.213,3,- }}{\text { Rp.2.000.000,- }} \times 100 \%=29,1 \%$

Dari hasil perhitungan di atas diperoleh bahwa sistem pemeliharaan yang telah diterapkan pada pabrik tahu super afifah sebesar 29,1\% berdasarkan Tabel 3.1 yang menyatakan jika hasil perhitungan dibawah $60 \%$ dikatakan sangat efisien.

2. Mesin Giling

Efisiensi $\frac{\text { Rp.1.492.799,9,- }}{\text { Rp.5.040.000,- }} \times 100 \%=29,6 \%$

Dari hasil perhitungan di atas diperoleh bahwa sistem pemeliharaan yang telah diterapkan pada pabrik tahu super afifah sebesar 29,6\% berdasarkan Tabel 3.1 yang menyatakan jika hasil perhitungan dibawah $60 \%$ dikatakan sangat efisien.

\section{Biaya Korektif}

1. Keter Uap

Efisiensi $\frac{\text { Rp. } 470.480,-}{\text { Rp.1.020.000,-- }} \times 100 \%=46,12 \%$

Dari hasil perhitungan di atas diperoleh bahwa sistem pemeliharaan yang telah diterapkan pada pabrik tahu super afifah sebesar $46,12 \%$ berdasarkan Tabel 3.1 yang menyatakan jika hasil perhitungan dibawah $60 \%$ dikatakan sangat efisien.

2. Mesin Giling

Efisiensi $\frac{\text { Rp.1.123.596,- }}{\text { Rp.2.550.000,- }} \times 100 \%=44,06 \%$

Dari hasil perhitungan di atas diperoleh bahwa sistem pemeliharaan yang telah diterapkan pada pabrik tahu super afifah sebesar 44,06\% berdasarkan Tabel 3.1 yang menyatakan jika hasil perhitungan dibawah $60 \%$ dikatakan sangat efisien.

\section{KESIMPULAN DAN SARAN}

\section{Kesimpulan}

Berdasarkan dari pembahasan dan analisis yang telah dikemukakan pada bab sebelumnya, maka peneliti dapat menarik suatu kesimpulan dari hasil penelitian tersebut yaitu biaya pemeliharaan yang telah diterapkan oleh pemilik pabrik tahu super afifah sangat efisien dengan nilai persentase untuk biaya pemeliharaan preventif dari keter uap sebesar 29,1\% dan untuk mesin giling sebesar 29,6\%, sedangkan untuk biaya perbaikan keter uap sebesar $46,12 \%$ dan untuk mesin giling sebesar $44,06 \%$. 


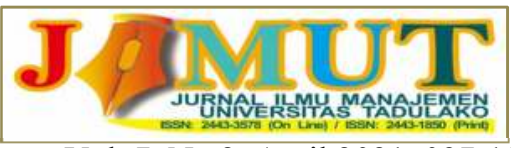

Vol. 7, No 2, April 2021, 097-106

\section{Saran}

Berdasarkan kesimpulan diatas penulis memberikan saran kepada pemilik pabrik tahu Super Afifah untuk kedepanya tetap menerapkan sistem pemeliharaan yang sudah ada saat ini agar biaya biaya pemeliharaan tetap efisien.

\section{REFERENSI}

Arikunto, 2006. Metode Penelitian yang mendapat Proposal. Jakarta: PT. Rineke Cipta.

Assauri, Sofjan., 2008. Manajemen Produksi dan Operasi, Edisi Revisi, Lembaga Penerbit Fakultas Ekonomi Universitas Indonesia, Jakarta.

Handoko, Hani T., 2014. Dasar-Dasar Manajemen Produksi Dan Operasi, Edisi Pertama, BPFE, Yogyakarta.

Mardiasmo, 2004., Efisiensi dan Efektivitas, Penerbit Jakarta.

Mobley, R. Keith. 2008. Maintenance Engineering Handbook, McGraw Hill, $7^{\text {th }}$ Edition,New York.

Prawirosentono, Suyadi., 2009. Manajemen Operasi (Operations management), Edisi Keempat, PT. Bumi Aksara, Jakarta.

Reksohadiprojo, Sukanto., 2003.Manajemen produksi dan Operasi, Edisi Keempat,

Subagyo, Pangestu., 2000. Manajemen Operasi, Edisi Pertama, BPFE, Yogyakarta.

Sugiyono, 2014. Metode Penelitian Kuantitatif, Kualitatif, dan R \& D. Alfabeta: Bandung

Yamit, Zulian, 2003. Manajemen Produksi dan Operasi Edisi Kedua Penerbit EKONISA Fakultas Ekonomi UII Yogyakarta. 